\title{
$1 \quad$ Facilitation and biodiversity jointly drive mutualistic networks
}

3 Gianalberto Losapio늘 Elizabeth Norton Hasday², Xavier Espadaler ${ }^{3}$, Christoph

4 Germann ${ }^{4}$, Javier Ortiz ${ }^{5}$, Adrian Pont ${ }^{6}$, Daniele Sommaggio ${ }^{7}$, Christian Schöb ${ }^{9}$

5

$6{ }^{1}$ Department of Biology, Stanford University, 94305 California, USA.

$7 \quad 2$ Department of Evolutionary Biology and Environmental Studies, University of Zurich,

$8 \quad 8057$ Zurich, Switzerland.

$9{ }^{3}$ CREAF, Autonomous University of Barcelona, 08193 Bellaterra, Spain.

104 Naturhistorisches Museum Basel, Augustinergasse 2, 4001 Basel, Switzerland.

$11{ }^{5}$ Grupo de Investigación "Transferencia de I+D en el Área de Recursos Naturales",

12 Universidad de Almería, E-04120 La Cañada Almería, Spain.

$13{ }^{6}$ Oxford University Museum of Natural History, Parks Road, Oxford OX1 3PW, UK.

$14{ }^{7}$ Department of Agricultural and Food Sciences, Alma Mater Studiorum-Università di

15 Bologna, 40127 Bologna, Italy.

$16{ }^{9}$ Department of Environmental Systems Science, ETH Zurich, 8092 Zurich, Switzerland.

18 Correspondence author: Gianalberto Losapio, losapiog@stanford.edu 


\section{ABSTRACT}

20 1. Facilitation by legume nurse plants increase understorey diversity and support

21 diverse ecological communities. In turn, biodiversity shapes ecological networks and

22 supports ecosystem functioning. However, whether and how facilitation and increased

23 biodiversity jointly influence community structure and ecosystem functioning remains

24 unclear.

25 2. We performed a field experiment disentangling the relative contribution of nurse

26 plants and increasing understorey plant diversity in driving pollination interactions to

27 quantify the direct and indirect contribution of facilitation and diversity to ecosystem

28 functioning. This includes analysing pollinator communities in the following treatment

29 combinations: (i) absence and presence of nurse plants, and (ii) understorey richness

30 with none, one and three plant species.

31 3. Facilitation by legume nurse plants and understorey diversity synergistically increase

32 pollinator diversity. Our findings reflect diverse assemblages in which complementarity

33 and cooperation among different plants result in no costs for individual species but

34 benefits for the functioning of the community and the ecosystem. Drivers of network

35 change are associated with increasing frequency of visits and non-additive changes in

36 pollinator community composition and pollination niches.

37 4. Synthesis Plant-plant facilitative systems, where a nurse shrub increases understorey

38 plant diversity, positively influences mutualistic networks via both direct nurse effects

39 and indirect plant diversity effects. Supporting such nurse systems is crucial not only for

40 plant diversity but also for ecosystem functioning and services.

42 Keywords 
43 Biodiversity, Ecological networks, Ecosystem function and services, Multi-trophic

44 interactions, Nurse plants, Plant-Plant-Insect interactions, Pollination, Retama

45 sphaerocarpa, Synergism, Woodland

\section{INTRODUCTION}

48 Ecologists started appreciating the importance of positive species interactions for

49 biological communities only in the last few decades (Connell \& Slatyer 1977; DeAngelis

50 et al. 1986; Hunter \& Aarssen 1988; Bertness \& Callaway 1994). Today, the fact that

51 plants provide wider benefits to other species and enhance biodiversity and ecosystem

52 functioning is a well-consolidated notion in ecology (Bruno et al., 2003; Callaway, 2007;

53 Levin, 2009; Keddy, 2017; Ellison, 2019). Likewise, the debate around the role of

54 diversity in the functioning and stability of ecological communities has been resolved in

55 favour of positive biodiversity effects (Chapin et al., 2000; Hooper et al., 2005; Tilman et

56 al., 2014; IPBES, 2019). Yet, whether and how facilitation and biodiversity jointly

57 influence community structure and ecosystem functioning remains less clear.

58 Although processes underpinning facilitation may be contingent on the organisms

59 involved and their environment (Brooker et al., 2008), as common in ecology (Lawton,

60 1999), facilitation is relevant to many different ecosystems (Callaway, 2007; McIntire \&

61 Fajardo, 2014; Liancourt \& Dolezal 2020) beyond specific communities (e.g., cushion

62 plants, kelp forests) and extreme environments (salt marshes, sand dunes, alpine

63 screes). Certain species called 'nurse plants' can ameliorate local environmental

64 conditions and increase biodiversity in their understorey and in the entire ecosystem

65 (Pugnaire, 2010; Butterfield et al., 2013; Cavieres et al., 2014; Rodríguez-Echeverría et

66 al., 2016; Ellison, 2019). By increasing both resources and biodiversity, plant facilitation

67 can ultimately increase ecosystem functioning, such as biomass production (Wright \& 
68 Jones, 2004; Michalet \& Touzard, 2010; Wright et al. 2017, Schöb et al. 2019) and the

69 flower visitation rate of pollinators (Losapio et al., 2019). However, whether plant

70 facilitation influences ecosystem functioning directly or indirectly through changes in

71 biodiversity remains largely unclear. Filling this knowledge gap is crucial for

72 understanding how biotic processes can stabilise ecosystem functioning.

73 Wright and colleagues (2017) proposed three main classes of facilitation

74 mechanisms that positively contribute to ecosystem functioning: (i) indirect biotic

75 facilitation, via reducing species-specific natural enemies (pathogens, herbivores); (ii)

76 abiotic facilitation via nutrient enrichment, such as the legume-rhizobia symbiosis that

77 directly increases nitrogen availability for neighbouring plants; (iii) abiotic amelioration

78 via improving microclimatic conditions. These mechanisms are deduced from literature

79 on biodiversity experiments carried out mainly on plant-species-richness gradient and

80 biomass productivity in temperate meadows (Jiang, Pu \& Nemergut, 2008). Thus, the

81 potential of such biodiversity experiments to gather generalizable knowledge is limited

82 to a small range of latitudes, systems, and ecological functions. Nevertheless, there is an

83 increasing number of studies showing that diversity effects also work beyond plant

84 communities (Schleuning et al., 2015; Rohr et al., 2020), and particularly across trophic

85 levels (Losapio et al., 2020). For example, increasing plant species richness increases

86 pollinator diversity and supports mutualistic network structure in temperate meadows

87 (Ebeling et al. 2008; Scherber et al. 2010; Blüthgen \& Klein 2011). Therefore, given that

88 nurse plants improve both abiotic and biotic aspects of ecosystems, ultimately

89 increasing biodiversity, and that plant diversity in turn increases pollinator diversity

90 and ecosystem functioning, it is reasonable to hypothesize that facilitation and therein

91 biodiversity have joint positive effects on mutualistic networks and ecosystem

92 functioning (Fig. 1). 
93 Here, we provide results of a study addressing this hypothesis and disentangling the

94 relative contribution of nurse plants and increasing understorey plant diversity in

95 driving pollination interactions. We asked the following questions: (i) What are the joint

96 effects of nurse plants and understorey plant diversity on the pollinator community? (ii)

97 What are the costs and benefits for the nurse plant in terms of pollination ? (iii) How do

98 facilitation and diversity shape pollination interactions and mutualistic networks?

1002 MATERIALS AND METHODS

$101 \quad 2.1$ Study system

102 We used a well-studied model system characterized by the nurse plant species Retama

103 sphaerocarpa (L.) BoISs. (Fabaceae), a legume shrub associated with the development of

104 "islands of fertility" under its canopy (Pugnaire et al., 1996; Schlesinger et al., 1996).

105 Thanks to the symbiotic, mutualistic interactions with Rhizobia bacteria hosted in their

106 roots, the inherent improvement of soil resources and overall amelioration of

107 microhabitat conditions, this legume nurse plant facilitates a wide diversity of

108 understorey plants (Moro et al., 1997; Armas, Rodríguez-Echeverría \& Pugnaire, 2011;

109 Rodríguez-Echeverría et al., 2013, 2016; Lozano et al., 2017). Furthermore, it produces

110 copious yellow blooms pollinated by diverse insects, including small-, medium-, and

111 large-sized Hymenoptera as well as several species of ants (Rodríguez-Riaño et al.,

112 1999).

113 As understorey, we selected three annual herbaceous species that commonly grow

114 with and without the nurse: Matricaria chamomilla L. (Asteraceae), Echium

115 plantagineum L. (Boraginaceae), and Carduus bourgeanus Boiss. \& Reut. (Asteraceae).

116 M. chamomilla has white and yellow flowers in an open capitulum, E. plantagineum has

117 purple tubular flowers along a raceme, and $C$ bourgeanus has blue flowers in a dense 
118 capitulum. These three species therefore represent a broad set of flower morphology

119 and pollination niches.

120 The study was carried out in an oak (Quercus ilex L.) savannah in a Mediterranean-

121 type ecosystem at the Aprisco de Las Corchuelas research station in Torrejón el Rubio,

122 Spain (39.81337 N -6.00022 W, 350 m a.s.l., mean rainfall of 637 mm/yr. and mean

123 annual temperature of $18^{\circ} \mathrm{C}$ ).

\section{$124 \quad 2.2$ Experimental design}

125 In order to disentangle the role of direct facilitation by the nurse from that of indirect

126 facilitation by the nurse through increased biodiversity on pollinators, and to further

127 examine their joint effects on mutualistic networks, a fully-factorial experimental design

128 including the following treatments was established (Fig. 1): (i) absence (open) and

129 presence of the legume shrub (nurse); (ii) understorey richness with one (1 sp) and

130 three (3 sp) plant species. This design results in the four treatment combinations of

131 open-1sp, open-3sp, nurse-1sp, and nurse-3sp. Furthermore, a nurse alone treatment

132 (nurse-0sp), i.e. a shrub without understorey plants, was included too. By comparing

133 mono- and poly-cultures, this design allowed us addressing the costs and benefits of

134 facilitation as well as the complementarity of plants for pollinators. A randomised block

135 design was adopted by grouping together the five treatments and replicating them three

136 times in each block over four blocks, for a total of $n=60$ plots. Distance between plots

137 within the same block was approx. $1 \mathrm{~m}$. Blocks were distributed randomly over an area

138 of about $4,800 \mathrm{~m}^{2}$.

139 Plant and understorey flower density were kept constant by transplanting plants in

140 pots. Pots were kept aggregated or sparse (c. $30 \mathrm{~cm}$ apart) below the nurse or in the

141 open. This additional factor was replicated per block. The same pots of understorey

142 plants were used for all blocks over two consecutive days before being replenished with 
143 fresh blooms. In the nurse alone treatment with no understorey species, three empty

144 pots with only soil were placed under the shrub to control for any potential effect of the

145 pots. For the nurse treatments, shrubs were chosen of approx. the same size (height

$146 \quad 127-178 \mathrm{~cm}$ and width $125-220 \mathrm{~cm}$ ). An area of $1 \mathrm{~m}^{2}$ at $1 \mathrm{~m}$ height was used as the

147 pollinator observation area in each shrub. Flowers of the surrounding vegetation within

148 at least $1 \mathrm{~m}$ around each shrub and open area were cleared.

149 Flower visitation was considered as a proxy for the ecosystem function of

150 pollination (Schleuning et al., 2015; IPBES, 2019). Flower visits were documented by

151 sampling, identifying, and recording all insects visiting the flowers of each plant in each

152 plot. Observations were conducted between 9 AM and 7 PM over eight days between 1

153 May and 14 May 2017, covering the blooming phase of the four plant species. Each plot

154 was observed during three slots of 20 min. randomly allocated over the day. Nurse

155 plants and corresponding open plots have been observed simultaneously, reducing the

156 disturbing effects of changing weather conditions within blocks. Each block was

157 sampled completely within two days. Pollinators were identified at the species level

158 whenever possible, otherwise to the genus. Specimens are conserved in $90 \%$ alcohol at

159 our institution collections.

$160 \quad 2.3$ Data analysis

161 To answer the first question, we calculated the abundance and richness of pollinators in

162 each plot, i.e., at the community level. We assessed the individual and combined effects

163 of facilitation (nurse presence vs absence) and diversity (understorey species richness)

164 on pollinator abundance and richness (two separate models) by means of Zero-inflated

165 Generalized Linear Mixed Modelling (Zi-GLMM) with a negative binomial distribution

166 (Brooks et al., 2017). Understorey aggregation was included as additional factor. Plant

167 species composition and plot nested within block were considered as random effects. 
168 To answer the second question, we calculated flower visits for each single plant 169 species in each plot and conducted cost-benefit analysis. For understorey plants, we 170 assessed the individual and combined effects of nurse shrubs and understorey species

171 richness on pollinator abundance by means of Zi-GLMM with a negative binomial

172 distribution. Understorey aggregation was included as additional factor. Plant species

173 identity and plot nested within block were considered as random effects. For nurse

174 shrubs, we assessed the effects of understorey species richness (nurse alone, 1 species

175 and 3 species; second-degree polynomial) on pollinator abundance by means of $\mathrm{Zi}$ -

176 GLMM with a negative binomial distribution. Understorey aggregation was included as

177 additional covariate. Understorey composition and plot nested within block were

178 considered as random effects.

179 To answer the third question, we used a framework based on the variance

180 partitioning of biodiversity effects (Loreau and Hector 2001) for the pollinator

181 community (Losapio et al., 2020). This framework allows comparing the net impact of a

182 diverse plant community on flower visits, distinguishing between complementarity and

183 selection effects (Loreau and Hector 2001; Wright et al. 2017; Losapio et al., 2020).

184 First, we calculated complementarity effects (CE) and selection effects (SE) among

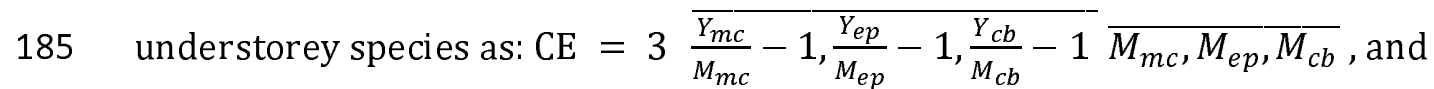

$186 \mathrm{SE}=3 \operatorname{cov}\left(\overline{\frac{Y_{m c}}{M_{m c}}-1, \frac{Y_{e p}}{M_{e p}}-1, \frac{Y_{c b}}{M_{c b}}-1}, \overline{M_{m c}, M_{e p}, M_{c b}}\right)$, where $Y$ and $M$ indicate flower

187 visits in polyculture (three understorey species) and monoculture (one understorey species),

188 respectively, for each understorey plant species (M. chamomilla, E. plantagineum, $C$.

189 bourgeanus). These effects were calculated both in the absence and presence of nurse

190 shrubs. This way, we tested the impact of plant facilitation on CE and SE. Then, the 191 diversity effects were tested in response to nurse presence, effect type, and their 
192 interaction using a linear model. Second, we calculated CE and SE between nurse shrubs

193 and understorey species. This way, nurse and understorey were considered as two

194 distinct functional groups. These functional diversity effects were calculated as:

$195 \mathrm{CE}=2 \overline{\frac{Y_{n s}}{M_{n s}}-1, \frac{Y_{u s}}{M_{u s}}-1} \overline{M_{n s}, M_{u s}}$, and SE $=2 \operatorname{cov}\left(\overline{\frac{Y_{n s}}{n s}-1, \frac{Y_{u s}}{M_{u s}}-1}, \overline{M_{n s}, M_{u s}}\right)$, where $Y$

196 and $M$ indicate flower visits in polyculture (two functional diversity groups of nurse and

197 understorey) and monoculture (nurse and understorey alone), respectively. These

198 effects were calculated with both one and three understorey species (nurse-1sp and

199 open-1sp; nurse-3sp and open-3sp). This way, we tested how CE and SE change with

200 plant diversity. Then, the diversity effects were tested in response to understorey

201 richness (categorical), effect type, and their interaction using a linear model.

202 To answer the third question, we built mutualistic networks between the four plant

203 species and each of their pollinator species (or genus) according to the additive matrix

204 framework (Losapio et al., 2019). This approach consists of building and comparing

205 observed networks (hereafter, 'synergistic') with 'additive' networks. 'Synergistic'

206 networks are built using the plant-pollinator interactions data collected from the

207 empirical plant community, here composed by the nurse shrub and the three

208 understorey species. Instead, 'additive' networks are built using data collected from the

209 four treatments of nurse shrub and understorey species monocultures and pooling

210 plant-pollinator interactions into a single 'additive' matrix.

211 To quantify network structure, we measured network eigenvector centrality

212 (Bonacich, 1987; Csardi \& Nepusz, 2006). This metric quantifies the extent to which

213 plant species with many pollinators are connected to pollinators that visit few species

214 or poorly connected plants interact with a few central pollinators. Then, to understand

215 the drivers of differences in mutualistic networks, we measured the dissimilarity 
216 between the networks using the framework of beta-diversity of species interactions

217 (Poisot, 2016). In particular, we considered the dissimilarity in species composition and

218 pairwise plant-pollinator interactions. In this case, networks were considered at the

219 block level. Network dissimilarity was calculated within 'additive' networks, within

220 'synergistic' networks, and between 'additive' and 'synergistic' networks. Differences

221 among networks were tested in response to the dissimilarity index (species or

222 interactions), dissimilarity within networks nested within dissimilarity between

223 networks, and their interaction using a linear model.

224 Statistical results are reported in terms of variances explained, using type-II ANOVA

225 (Fox \& Weisberg, 2019), and parameter estimates with 95\% Confidence Interval. In case

226 of significant statistical interactions, contrasts among factor combinations were

227 computed using estimated marginal means (Lenth, 2020).

2293 RESULTS

\section{$230 \quad 3.1$ Pollinator community}

231 We found that both nurse presence $(P<0.001)$ and diversity $(P=0.002)$ significantly

232 explain differences in visitor abundance at the community level (Fig. 2a), whereas

233 aggregation and the interaction between nurse presence and diversity were not

234 significant. In particular, the nurse shrub increases flower visitor abundance by $68 \%$

235 compared to open $(\beta, 95 \% \mathrm{CI}=1.72,0.99-2.45)$. Furthermore, increasing understorey

236 plant diversity from one to three species increases flower visitor abundance by $19 \%$

$237(0.56,0.22-2.92)$.

238 Similarly, nurse presence $(P<0.001)$, diversity $(P=0.002)$ and their statistical

239 interaction $(P=0.040)$ significantly influence pollinator species richness (Fig. $2 \mathrm{~b}$ ),

240 whereas aggregation was not significant. On average, the presence of the nurse shrub 
241 increases the richness of the pollinator community by $74 \%(1.6,1.07-2.13)$, and

242 increasing understorey plant diversity from one to three species increases richness by

$24324 \%(0.34,0.15-0.54)$. Furthermore, nurse presence and understorey diversity jointly

244 influence pollinator richness, being the effects of diversity stronger in open $(c=0.69 \pm$

$2450.20 \mathrm{SE}, P=0.005)$ than underneath the nurse canopy $(c=0.19 \pm 0.14 \mathrm{SE}, P=0.495)$,

246 and the effects of nurse presence stronger at low diversity $(c=1.35 \pm 0.17, P<0.001)$

247 than high diversity $(c=0.86 \pm 0.17 \mathrm{SE}, P<0.001)$.

\section{$248 \quad 3.2$ Benefits and costs}

249 We then explored the effects of facilitation and diversity on flower visitation rate per

250 each species. Considering understorey plants, diversity had significant effects on flower

251 visits $(P<0.001)$, which was independent of aggregation, nurse presence or its

252 interaction (Fig. 3a). In particular, increasing understorey diversity increased the

253 number of flower visits on each understorey species by $34 \%(0.40,0.14-0.54)$. Variance

254 among species was low (0.013).

255 Considering the legume nurse shrub, both aggregation and diversity significantly

256 influenced visitation rate $(P=0.045$ and $P=0.002$, respectively). In particular,

257 aggregating understorey plants increased visitor abundance for the nurse shrub by $10 \%$

$258(0.39,0.01-0.76)$. Understorey diversity had non-linear effects on nurse's visitors (Fig.

$2593 \mathrm{~b}$ ), being positive only at high richness (quadratic term $2.28,0.98-3.59$ ).

\section{$260 \quad 3.3$ Complementarity and selection effects}

261 We then explored diversity effects (i.e. complementarity and selection effects) among

262 understorey species (Fig. 4a) and between nurse and understorey (Fig. 4b). In the case

263 of understorey species richness, we found that diversity effects were independent of

264 nurse shrubs but significantly varied between complementarity and selection effects $(P$

$265<0.001$ ), since selection effects were more negative than complementarity effects 
266 positive (Fig. 4a). In particular, complementarity effects were marginally positive in the

267 absence and presence of nurse shrubs (499, -33.1-1031; 517, -15.5-1049), respectively,

268 while selection effects were negative in both cases $(-754,-1286.3--222 ;-771,-1302.9-$

$269-238)$.

270 In the case of the nurse-understorey combination, diversity effects between nurse

271 and understorey plants changed with understorey species richness $(P=0.033)$

272 depending on effect type $(P=0.009)$. While complementarity effects significantly

273 increased with increasing understorey richness ( $c=160.0 \pm 41.1 \mathrm{SE}, P=0.002)$,

274 selection effects remained the same $(c=20.1 \pm 41.4 \mathrm{SE}, P=0.495)$. Furthermore,

275 complementarity effects were negative and positive at low and high richness $(-124.6,-$

276 188.3--60.89; 36.2, -27.5-99.93), respectively, while selection effects were always

277 marginally negative $(-38.5,-102.2-25.26 ;-58.6,-122.3-5.14)$.

\section{$278 \quad 3.4$ Network change}

279 Finally, we explored mutualistic network centrality and dissimilarity between additive

280 and synergistic networks. We found that synergistic networks were significantly less

281 centralized than additive networks $(\beta=-0.35, P<0.001$, Fig. 5). Considering

282 components of network dissimilarity, species turnover was twice as high as interaction

283 change overall ( $c=0.20 \pm 0.02 \mathrm{SE}, P<0.002)$, with dissimilarity in interaction change

284 between synergistic networks being lower relative to dissimilarity in species

285 composition between additive networks (-0.14, -0.25- -0.02).

\section{DISCUSSION}

288 Species interactions and biodiversity play a crucial role in shaping ecological networks

289 and supporting ecosystem functioning, yet their joint effects remain poorly understood.

290 Now we provide new evidence for the mingled consequences of plant facilitation and 
291 diversity for mutualistic networks of pollination, a key ecosystem function. The results

292 of our field experiment indicate that facilitation by legume nurse shrubs and

293 understorey diversity synergistically increase the diversity of pollinators. Our findings

294 reflect diverse assemblages in which complementarity and cooperation among different

295 plants result in no costs for individual species but benefits for the functioning of the

296 community and the ecosystem.

\section{$297 \quad 4.1$ Community-scale benefits}

298 Results support the hypotheses that facilitation and biodiversity jointly influence

299 mutualistic networks and ecosystem functions, as both nurse shrub and understorey

300 diversity increase pollinator abundance and richness at the community level.

301 Facilitation can positively influence ecological networks beyond plant communities,

302 including pollination networks (Losapio et al., 2019), arthropod food-webs (van der Zee

303 et al., 2016), mammal communities (Lortie et al., 2016), and soil microorganisms

304 (Rodríguez-Echeverría et al., 2013). Notably, benefits of facilitation involve not only the

305 plant community itself but also scale up to flower visitors, whose diversity increases in

306 nurse-understorey assemblages. Thus, the amelioration of biophysical environment by

307 legume nurse shrubs favours both understorey species (Pugnaire 2010), directly via

308 microhabitat improvement and indirectly via enhanced pollination, the plant

309 community as a whole as well as the pollinator network. Underlying mechanisms may

310 be enhanced floral display via increasing community-level attractiveness to generalist

311 pollinators (Losapio et al. 2019), i.e., 'cluster effect' (Krugman, 1991), and service

312 sharing (McIntire \& Fajardo, 2014). Moreover, enhanced floral resources via soil

313 symbionts of the legume nurse shrub (Harris, 2009; Rodríguez-Echeverría et al., 2016)

314 may also be responsible for improving floral attractiveness in natural conditions. 
315 Besides nurse shrub presence, increasing understorey diversity increases pollinator

316 diversity, as the higher the floral diversity the higher the availability of resources for

317 pollinators in polyculture as compared to monoculture. These results are consistent

318 with previous studies showing that plant diversity, along with the co-varying factors

319 including blossom cover and presence of particularly attractive flowering species,

320 enhances both the frequency and the temporal stability of pollinator visits (Ebeling et

321 al., 2008). In addition, flower visits increase with plant diversity when diverse flower

322 displays increase the duration of flower provision (Fornoff et al., 2017) and widen

323 pollination niches (Losapio et al., 2020). Since plant and flower density were kept

324 constant in our experiment, the positive effects of understorey diversity on ecosystem

325 functions are mainly driven by pollination niche complementarity and loss of poorly-

326 attractive species, as discussed in the paragraph below (4.2).

327 Notably, the combination of facilitation and diversity effects produce even greater

328 benefits for mutualistic networks than expected by these two factors alone. In fact,

329 adding more understorey species (at constant plant and flower density) produce

330 stronger effects on pollinator diversity in the absence of nurse shrubs as compared to

331 their presence. That is, facilitation and diversity synergistically interact to influence

332 ecosystem functioning. This is most likely due to the overwhelming facilitative effects of

333 nurse shrubs and the non-linear nature of community assembly processes. The

334 presence of nurse shrubs seems more important at low diversity, while increasing

335 diversity seems more relevant in the absence of facilitation. Most importantly, our

336 results show that plant-plant facilitation is an important driver of mutualistic networks

337 and ecosystem functioning, both directly and indirectly via increasing biodiversity.

338 Cost-benefit analysis reveals that species-specific pollination facilitation results in

339 neutral net effects for both nurse and understorey species and positive net effects of 
340 biodiversity. That is, the benefits of facilitation for the whole community come at no

341 costs for the individual species. It is not surprising that nurse shrubs do not necessarily

342 increase flower visitation of understorey species, as the outcome of specific facilitation

343 mechanisms is often context-dependent and varies in the short term (Montesinos-

344 Navarro et al., 2019). In fact, facilitation for vegetative reproduction (establishment,

345 growth, survival) can be independent from facilitation for sexual reproduction (Losapio

346 et al., 2019). Interesting enough, the positive effects of biodiversity scale from

347 communities to single species since there is a correspondence between increasing

348 ecosystem functioning and increasing species visits. This is not always the case for

349 biodiversity experiments, where an increase in community productivity does not

350 necessarily follow an increase in species-specific biomass (Tilman et al., 2014).

\section{$351 \quad 4.2$ Complementarity and selection effects}

352 The current understanding of the relationships between biodiversity and ecosystem

353 functioning comes primarily from studies focusing on the effects of plant species

354 richness on biomass production in temperate meadows (Jiang et al., 2008). While

355 competition is often claimed to play a role in such system, facilitation is overlooked or

356 lumped within several less explicitly defined processes as complementarity effects

357 (Blüthgen \& Klein 2011; Wright et al., 2017). The experimental framework we adopted

358 here allows us manipulating both taxonomic and functional diversity in combination

359 with facilitation, then measuring complementarity among understorey species as well

360 as between nurse shrubs and understorey plants.

361 Our results indicate positive complementarity effects among understorey species.

362 Furthermore, complementarity between nurse and understorey species increases with

363 diversity. Results also indicate negative selection effects, suggesting that species with

364 generally few pollinators benefit the most in the polyculture (understorey species), 
365 while a species (possibly the nurse plant) with generally lots of pollinators does not.

366 These provide new evidence for a novel facilitation process based on community-scale

367 facilitation (Callaway, 2007; Liancourt \& Dolezal 2020) and on the 'cluster effect'

368 (Krugman, 1991; Losapio et al., 2019) at different trophic levels: diverse flower

369 assemblages including nurse shrubs are more attractive than monocultures thanks to

370 increased visibility of the community as a whole for attracting a wider spectrum of

371 visitors.

372 This way, being part of the polyculture cluster (nurse shrub with diverse

373 understorey) would increase the chances of being visited, and eventually pollinated.

374 Joint effects of diversity and community-scale facilitation involve not only the plant

375 community itself but also flower visitors, whose diversity increased in nurse-

376 understorey assemblages. Thus, the amelioration of the biophysical environment by

377 legume nurse shrubs favours understorey species (Pugnaire 2010), directly via

378 microhabitat improvement and indirectly via enhanced pollination, but also the plant

379 community as a whole and its ecosystem functions.

\section{$380 \quad 4.3$ Network change}

381 By means of the additive matrix framework (Losapio et al., 2019), we compared

382 synergistic networks that emerge from the plant community as a whole with additive

383 networks that result from pooling plant species as separate components. These two

384 networks appear to be very different, highlighting the non-additivity of nurse and

385 understorey plants. This shows that interactions among plants influence interactions

386 between plants and pollinators. In particular, facilitative interactions among nurse and

387 understorey plants influence pollination networks by changing the identity and

388 frequency of flower visitors. Such nonadditive interactions change network structure,

389 making the network more de-centralised than expected by additive effects, which may 
390 ultimately improve the overall resistance and stability of pollinator communities

391 (Blüthgen \& Klein 2011). Furthermore, our results show that synergistic networks were

392 more similar among each other in terms of species interactions as compared to the

393 higher dissimilarity of species interactions observed among 'additive' networks. Drivers

394 of network change are associated with increasing frequency of visits and potentially

395 pollinator population density, thus affecting interaction strength, as well as changes in

396 floral attractiveness and pollination niches, which ultimately promote species turnover

397 and interaction rewiring.

398 Notice that this is different from a case of pollination facilitation (Feldman et al.,

399 2004; Gazhoul, 2006; Braun \& Lortie 2019), where the presence of a plant increases

400 pollination of a neighbour, but the two do not always interact directly, e.g., facilitating

401 germination and survival (Losapio and Schöb 2020). In the present case study, plant

402 species are interacting directly via changes in microhabitat conditions and soil

403 symbionts. Furthermore, we now show that they also interact indirectly via pollination

404 networks.

405 In conclusion, our study shows that plant-plant facilitative systems where a nurse

406 shrub increases understorey plant diversity positively influences pollination networks

407 via both direct nurse effects and indirect plant diversity effects.

408

409 Acknowledgements

410 GL and CS are grateful for financial support by the Swiss National Science Foundation

411 (P2ZHP3_187938, PZ00P3_148261 and PP00P3_170645). 
414 GL and CS designed the study; EN conducted the experiment; LC, XE, CG, JO, AP and DS

415 identified the specimens; GL analysed the data and wrote the manuscript with inputs

416 from CS. All authors commented and approved the final publication.

417 The authors have declared no competing interest.

419 Data availability

420 The dataset will be published in the in the Dryad Digital Repository upon manuscript

421 acceptance.

422

423 References

424 Armas, C., Rodríguez-Echeverría, S., Pugnaire, F.I. (2011) A field test of the stress-

425 gradient hypothesis along an aridity gradient. Journal of Vegetation Science, 22, 818-

$426 \quad 827$.

427 Bates, D., Maechler, M., Bolker, B., Walker, S. (2015) Fitting Linear Mixed-Effects Models

428 Using lme4. Journal of Statistical Software, 67, 1-48.

429 Bertness, M.D., Callaway, R. (1994) Positive interactions in communities. Trends in

$430 \quad$ Ecology and Evolution, 9, 191-193.

431 Blüthgen, N., Klein, A. (2011) Functional complementarity and specialisation: the role of

432 biodiversity in plant-pollinator interactions. Basic and Applied Ecology, 12, 282-291.

433 Bonacich, P. (1987) Power and Centrality: A Family of Measures. American Journal of

$434 \quad$ Sociology, 92, 1170-1182.

435 Braun, J., Lortie, C.J. (2019) Finding the bees knees: A conceptual framework and

436 systematic review of the mechanisms of pollinator-mediated facilitation.

437 Perspectives in Plant Ecology, Evolution and Systematics, 36, 33-40. 
438 Brooker, R.W., Maestre, F.T., Callaway, R.M., et al. (2008) Facilitation in plant

439 communities: the past, the present, and the future. Journal of Ecology, 96, 18-34.

440 Brooks, M.E., Kristensen, K., van Benthem, K.J., Magnusson, A., Berg, C.W., Nielsen, A.,

441 Skaug, H.J., Maechler, M., Bolker, B.M. (2017). glmmTMB Balances Speed and

442 Flexibility Among Packages for Zero-inflated Generalized Linear Mixed Modeling.

443 The R Journal, 9, 378-400.

444 Bruno, J.F., Stachowicz, J.J., Bertness, M.D. (2003) Inclusion of Facilitation into Ecological

445 Theory. Trends in Ecology and Evolution, 18, 119-125.

446 Butterfield, B.J., Cavieres, L.A., Callaway, R.M. (2013) Alpine cushion plants inhibit the

447 loss of phylogenetic diversity in severe environments. Ecology Letters, 16, 478-486.

448 Callaway, R.M. (2007) Positive interactions and interdependence in plant communities.

$449 \quad$ Springer, The Netherlands.

450 Cavieres, L.A., Broojer, R.W., Butterfield, B.J., et al. (2014) Facilitative plant interactions

451 and climate simultaneously drive alpine plant diversity. Ecology Letters, 17, 193-

$452 \quad 202$.

453 Chapin, F.S., Zavaleta, E.S., Eviner, V.T., et al. (2000) Consequences of changing

$454 \quad$ biodiversity. Nature, 405, 234-242.

455 Csardi, G., Nepusz, T. (2006) The igraph software package for complex network

456 research. International Journal Complex Systems, 1695. 2006. http://igraph.org

457 Connell, J. H., Slatyer, R. O. (1977) Mechanisms of succession in natural communities

458 and their role in community stability and organization. The American Naturalist,

459 111, 1119-1144.

460 DeAngelis, D.L., Post, W.M., Travis, C.C. (1986) Positive Feedback in Natural Systems.

461 Springer, Berlin, Germany. 
462 Ebeling, A., Klein, A.M., Schumacher, J., Weisser, W.W., Tscharntke, T. (2008) How does

463 plant richness affect pollinator richness and temporal stability of flower visits?

$464 \quad$ Oikos, 117, 1808-1815.

465 Ellison, A.M. (2019) Foundation species, Non-trophic interactions, and the value of

466 being common. iScience, 13, 254-268.

467 Feldman, T. S., Morris, W. F., \& Wilson, W. G. (2004). When can two plant species

468 facilitate each other's pollination? Oikos, 105(1), 197-207.

469 Fox, J. \& Weisberg, S. (2019). An $\{$ R $\}$ Companion to Applied Regression, Third Edition.

470 Thousand Oaks CA: Sage. URL:

471

$\underline{\text { https://socialsciences.mcmaster.ca/ifox/Books/Companion/ }}$

472 Gazhoul, J. (2006) Floral diversity and the facilitation of pollination. Journal of Ecology,

$473 \quad 94,295-304$.

474 Hooper, D.U., Chapin, F.S., Ewel, J.J., et al. (2005) Effects of biodiversity on ecosystem

475 functioning: a consensus of current knowledge. Ecological Monographs, 75, 3-35.

476 Hunter, A.F., Aarssen, L.W. (1988) Plants helping plants. Bioscience, 38, 34-40.

477 Keddy, P. (2017) Plant Ecology: Origins, Processes, Consequences. Cambridge University

$478 \quad$ Press, UK.

479 IPBES (2019) Global assessment report on biodiversity and ecosystem services of the

$480 \quad$ Intergovernmental Science-Policy Platform on Biodiversity and Ecosystem Services. E.

481 S. Brondizio, J. Settele, S. Díaz, and H. T. Ngo (editors). IPBES secretariat, Bonn,

482 Germany.

483 Krugman, P. (1991). Geography and Trade. MIT Press.

484 Jiang, L., Pu, Z. \& Nemergut, D.R. (2008) On the importance of the negative selection

485 effect for the relationship between biodiversity and ecosystem functioning. Oikos,

$486 \quad 117,488-493$. 
487 Lawton, J.H. (1999) Are there general laws in ecology? Oikos, 84, 177-192.

488 Lenth, R. (2020). emmeans: Estimated Marginal Means, aka Least-Squares Means. R

489 package version 1.4.8. https://CRAN.R-project.org/package=emmeans

490 Levin, S.A. (2009) The Princeton Guide to Ecology. Princeton University Press, USA.

491 Liancourt, P., Dolezal, J. (2020) Community-scale effects and strain: Facilitation beyond 492 conspicuous patterns. Journal of Ecology, in press.

493 Loreau, M., Hector, A. (2001) Partitioning selection and complementarity in biodiversity 494 experiments. Nature, 412, 72-76.

495 Lortie, C.J., Filazzola, A. and Sotomayor, D.A. (2016), Functional assessment of animal 496 interactions with shrub-facilitation complexes: a formal synthesis and conceptual 497 framework. Functional Ecology, 30, 41-51.

498 Losapio, G., Fortuna, M.A., Bascompte, J., et al. (2019) Plant interactions shape

499 pollination networks via nonadditive effects. Ecology, 100, e02619.

500 Losapio, G., Schmid, B., Bascompte, J., et al., (2020) Assessing the impact of ecosystem

501 engineers on biodiversity and ecosystem functions across trophic levels.

$502 \quad$ Unpublished data.

503 Losapio, G., Schöb, C. (2020) Pollination interactions reveal direct costs and indirect

504 benefits of plant-plant facilitation for ecosystem engineers. Journal of Plant Ecology,

$505 \quad$ 13, 107-113.

506 Lozano, Y.M., Armas, C., Hortal, S., Casanoves, F., Pugnaire, F.I. 2017. Disentangling

507 above- and below-ground facilitation drivers in arid environments: the role of soil

508 microorganisms, soil properties and microhabitat. New Phytologist, 216, 1236-

$509 \quad 1246$.

510 McIntire, E.J., Fajardo, A. (2014) Facilitation as a ubiquitous driver of biodiversity. New $511 \quad$ Phytologist, 201, 403-416. 
512 Michalet, R., Touzard, B. (2010) Biotic interactions, biodiversity, and community

513 productivity. In (eds. F.I. Pugnaire) Positive plant interactions and community

514 dynamics. Taylor \& Francis, USA.

515 Moro, M. J., Pugnaire, F. I., Haase, P., \& Puigdefabregas, J. (1997). Effect of the Canopy of

516 Retama sphaerocarpa on Its Understorey in a Semiarid Environment. Functional

$517 \quad$ Ecology, 11, 425-431.

518 Poisot, T. (2016). betalink: Beta-Diversity of Species Interactions. R package version

519 2.2.1. https://CRAN.R-project.org/package=betalink

520 Pugnaire, F.I., Haase, P., Puigdefabregas, J. (1996) Facilitation between higher plant

$521 \quad$ species in a semiarid environment. Ecology, 77, 1420-1426.

522 Rodríguez-Echeverría S, Armas C, Pistón N, Hortal S, Pugnaire FI. 2013. A role for below

523 ground biota in plant-plant facilitation. Journal of Ecology 101: 1420-1428.

524 Rodríguez-Echeverría S, Lozano YM, Bardgett RD. 2016. Influence of soil microbiota in

525 nurse plant systems. Functional Ecology 30: 30-40.

526 Rodríguez-Riaño, T., Ortega-Olivencia, A. \& Devesa, J.A. (1999) Reproductive phenology

527 in three Genisteae (Fabaceae) shrub species of the W Mediterranean Region. Nordic

$528 \quad$ J. Bot. 19: $345-3$

529 Rohr, J.R., Civitello, D.J., Hlliday, F.W., Hudson, P.J., Lafferti, K., Wood, C.L., Mordecai, E.A.

530 (2020) Towards common ground in the biodiversity-disease debate. Nature Ecology

$531 \quad$ \& Evolution, 4, 24-33

532 Scherber, C., Eisenhauer, N., Weisser, W., et al. (2010) Bottom-up effects of plant

533 diversity on multitrophic interactions in a biodiversity experiment. Nature, 468,

$534 \quad 553-556$.

535 Schlesinger, W.H, Raikes, J.A., Hartley A.E., Cross, A.F. (1996) On the Spatial Pattern of

536 Soil Nutrients in Desert Ecosystems. Ecology, 77, 364-374. 
537 Schleuning, M., Fründ, J., García, D. (2015) Predicting ecosystem functions from

538 biodiversity and mutualistic networks: an extension of trait-based concepts to

539 plant-animal interactions. Ecography, 38, 380-392.

540 Schöb, C., Brooker, R.W., Zuppinger-Dingley, D. (2018) Evolution of facilitation requires

541 diverse communities. Nature Ecology \& Evolution, 2, 1381-1385.

542 Tilman, D., Isbell, F., Cowles, J.M. (2014) Biodiversity and Ecosystem Functioning.

543 Annual Review of Ecology, Evolution, and Systematics, 45, 471-493.

544 Wright, A.J., Wardle, D.A., Callaway, R., Gaxiola, A. (2017) The overlooked role of

545 facilitation in biodiversity experiments. Trends in Ecology and Evolution, 32, 383-

$546 \quad 390$.

547 Wright, JP, Jones, C.G.P. (2004) Predicting effects of ecosystem engineers on patch-scale 548 species richness from primary productivity. Ecology, 85, 2071-2081. 


\section{$550 \quad$ Figures and tables}

551
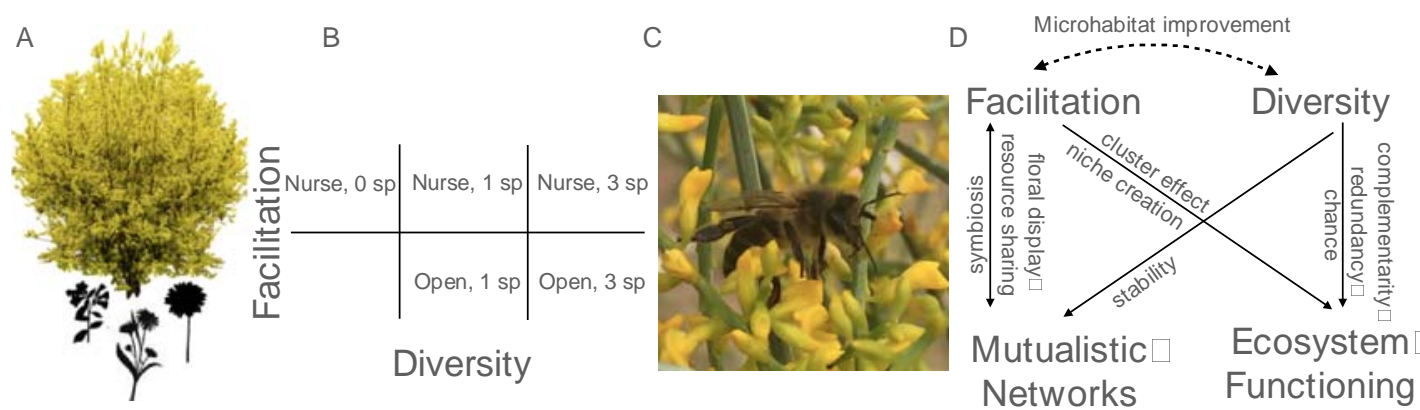

552 Fig. 1 Conceptual framework and experimental design. (A) A legume nurse shrub

553 (Retama sphaerocarpa) facilitates diverse herbaceous plant species in the understorey.

554 (B) To examine the joint effects of plant facilitation and biodiversity change on

555 mutualistic networks, the experimental design includes the treatments of nurse

556 presence/absence and understorey species richness. Plant and flower density of

557 understorey species were kept constant. Furthermore, a nurse alone treatment (i.e.,

558 shrub without understorey plants) was included. (C) We then examined the response of

559 pollination interactions, such as those between Apis mellifera and Retama sphaerocarpa.

560 (D) Process pathways among facilitation, diversity, mutualistic networks and ecosystem

561 functioning. 


\section{A}

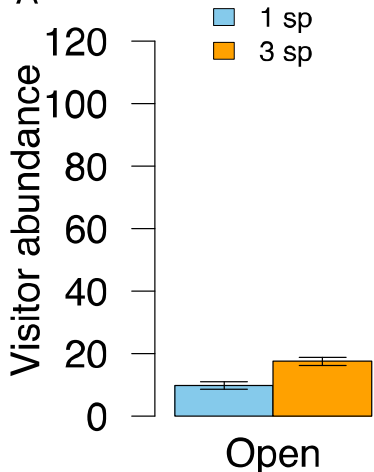

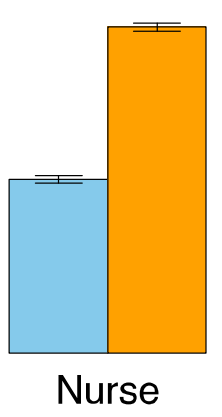

$\begin{aligned} & \mathrm{B} \\ & \square \\ & \square 1 \mathrm{sp} \\ & \square 3 \mathrm{sp}\end{aligned}$

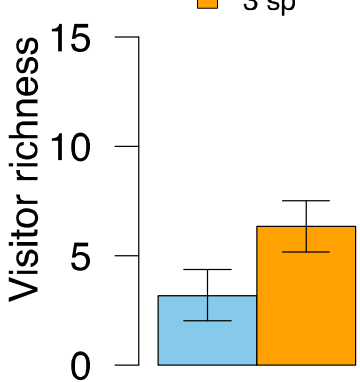

Open

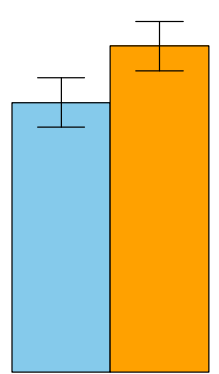

Nurse

564 Fig. 2 Effects of facilitation (open vs nurse) and biodiversity ( 1 vs 3 species) on

565 abundance (A) and richness (B) of the pollinator community (i.e., flower visitors) per

566 plot. Bars indicate SE.

567 
A

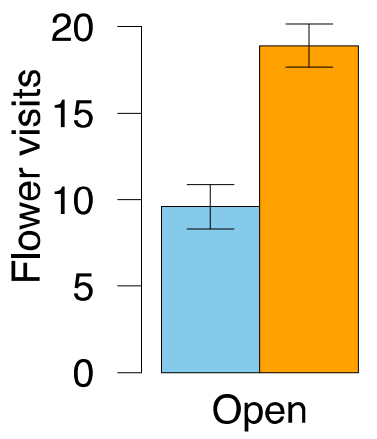

$\square 1 \mathrm{sp}$

$\square 3 \mathrm{sp}$

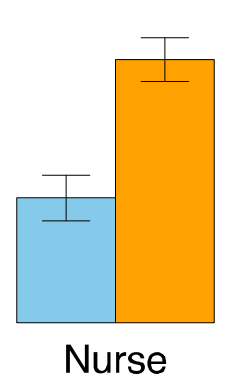

B

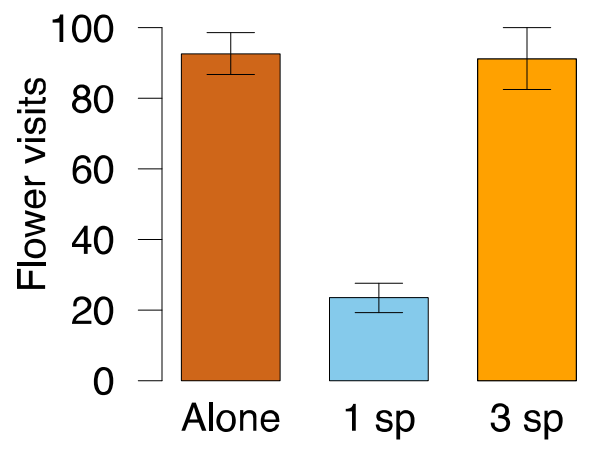

569 Fig. 3 Cost and benefit analysis of facilitation (open vs nurse) and biodiversity (1 vs 3

570 understorey species) for understorey plants (A) and nurse shrubs (B) in each plot. Bars

571 indicate SE. 

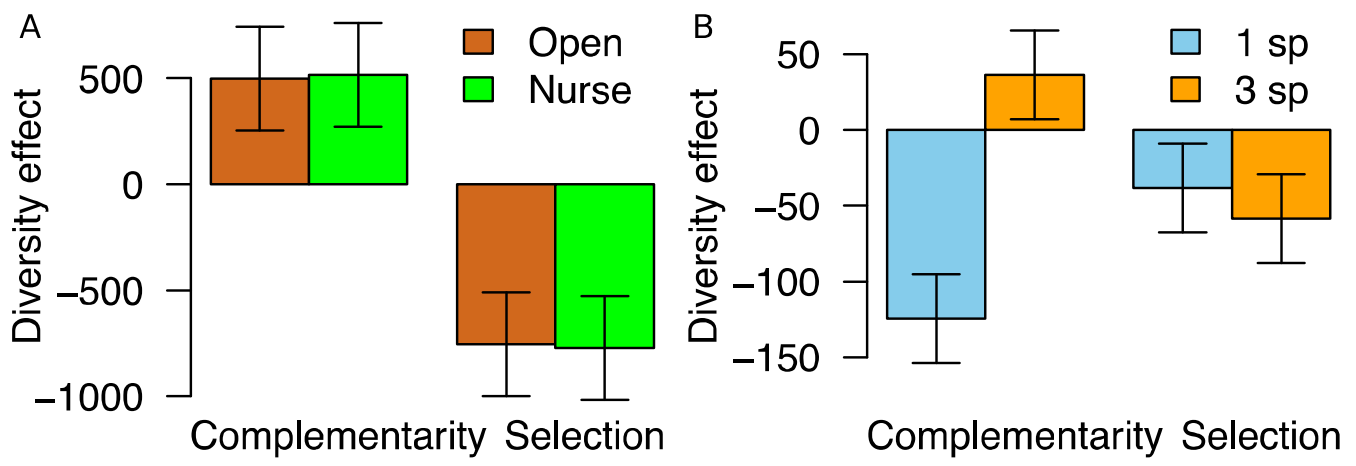

574 Fig. 4 Consequences of facilitation (open vs nurse) for complementarity and selection

575 effects among understorey species (A). Complementarity and selection effects between

576 nurse plants and understorey species (B). Bars indicate SE. 
bioRxiv preprint doi: https://doi.org/10.1101/2020.08.25.266346; this version posted August 25, 2020. The copyright holder for this preprint (which was not certified by peer review) is the author/funder, who has granted bioRxiv a license to display the preprint in perpetuity. It is made available under aCC-BY-NC 4.0 International license.

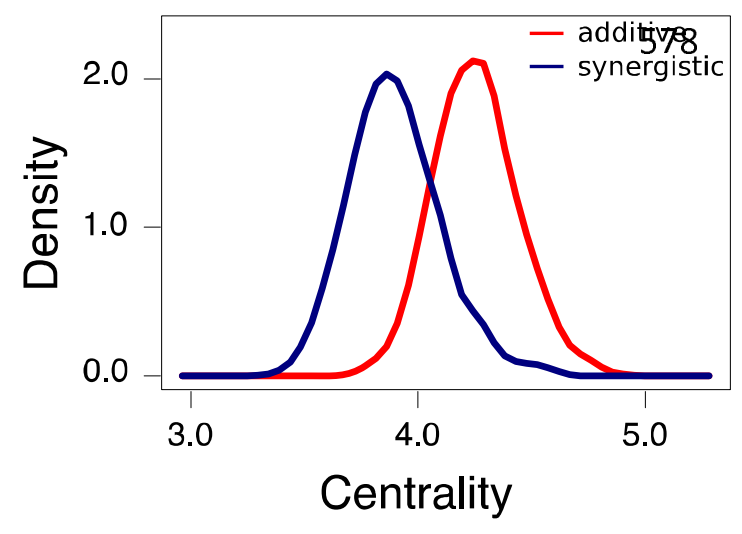

579

580 Fig. 5 Network centrality of additive networks (red) and synergistic networks (blue). 